\title{
Prevalence of obesity and overweight among urban adults in Bulgaria
}

\author{
Lumdila Ivanova', Plamen Dimitrov', Jocilyn Dellava ${ }^{2}$ and Daniel Hoffman ${ }^{2, *}$ \\ ${ }^{1}$ National Center of Public Health Protection, Sofia, Bulgaria: ${ }^{2}$ Department of Nutritional Sciences, \\ Rutgers University, 26 Nichol Avenue, Room 228B, New Brunswick, NJ 08901, USA
}

Submitted 25 June 2007: Accepted 13 February 2008: First published online 15 April 2008

\begin{abstract}
Objective: The prevalence of obesity is increasing in transitional countries, but extensive data on some countries, such as Bulgaria, are still lacking. Therefore, the objective of the present study was to estimate the prevalence of overweight and obesity, relative to gender and income, among adults in Sofia, Bulgaria.

Design: Cross-sectional survey to collect data on diet, health, BMI and income using a brief questionnaire on diet and income. Data were analysed using analysis of covariance to determine differences within and between income and gender groups.

Setting: Sofia, Bulgaria.

Subjects: Adults living in the city of Sofia, Bulgaria.

Results: For adults 30-60 years of age, 35.1\% were overweight and 6.2\% were obese. The proportion of overweight and obesity was higher among men than women $(44 \cdot 8 \% \quad v \cdot 32 \cdot 4 \%$ and $6 \cdot 0 \% \quad v .4 \cdot 7 \%$, respectively). With respect to income, BMI decreased as income increased. For men, BMI was highest for the lowest and highest income groups, whereas for women lower income was associated with a higher BMI.

Conclusion: The prevalence of overweight and obesity appears to be an emerging problem in some sectors of Bulgarian society, based on our data from the largest urban area of the country. These data provide new information on the divergence in health and disease risk in a country that is still economically challenged and may be facing the nutrition transition.
\end{abstract}

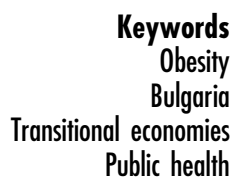

Obesity

Bulgaria

Public health
Obesity is a major public health problem that contributes to an increased prevalence of chronic diseases ${ }^{(1,2)}$. For countries undergoing rapid socio-economic transitions, changes in food marketing or economic structuring may contribute to an increased prevalence of obesity ${ }^{(3-5)}$. Bulgaria, a transitional country recently admitted into the European Union (EU), faces such changes following economic crises and nutritional challenges after the fall of the Soviet Union and a shift from a centralized to a market economy $^{(6,7)}$. While these changes have been slow and difficult to measure, the exact result on health and diet is important because the country underwent significant crises in terms of inflation and income and rapid structural shifts in food production and distribution.

Recently, we reported that the dietary trends following the shift from a centralized to a market economy in Bulgaria showed a general downward intake of reported energy consumption ${ }^{(8)}$. At the same time, it is important to note that Bulgaria has had a rather unique history in terms of diet and disease patterns, one that is not paralleled by other countries in the former Eastern Bloc. For example, in Poland, following the shift to a market economy, there was a shift from a diet high in vegetables and low in protein to a diet high in sugar, protein and fat $^{(9)}$. The former Soviet Union suffered an opposite fate in that the diet of average persons became worse as the economy faltered during the early $1990 \mathrm{~s}^{(5)}$. However, Bulgaria maintained a productive dairy and livestock industry and a generally healthful diet through the 1980s. Still, the collapse of the Soviet Union, accompanied by structural change, economics crises and labour shifts in the 1990s, may have prompted a downturn in terms of dietary intake and quality that could promote disease and poor health.

However, few longitudinal data are available on the prevalence of overweight and obesity in Bulgaria, especially with respect to income ${ }^{(10)}$. Moreover, the only reports on adult BMI in Bulgaria come from clinical studies limited in size and scope ${ }^{(6,7)}$. This is a particularly important point given that Bulgaria is on the verge of 
significant economic development and may begin to experience the emergence of dietary shifts associated with obesity. Therefore, the objective of the present study was to determine the prevalence of overweight and obesity, relative to income, in adults living in Sofia, Bulgaria.

\section{Methods}

A cross-sectional survey of adults was conducted in Sofia in 2004-2006 as part of a comprehensive survey on diet and food shopping preferences. From the twenty-five voting districts in the city of Sofia, six voting districts were randomly selected from which various retail sites - public markets, small stores (with one cashier), small grocery stores (with two to five cashiers) and large supermarkets (with ten or more cashiers) - were randomly selected. A trained research assistant approached every third customer exiting the store, inviting him/her to participate in the study (refusal rate was estimated at $10 \%$ ). A total of 1006 adults, 453 males and 553 females, volunteered for the study and all signed a written informed consent, but only 871 reported their income.

Each participant was weighed in minimal clothing, without sweaters, jackets or shoes, using a digital scale (TAURUS Inx., range of $5-130 \mathrm{~kg}$, precision $\pm 0.5 \mathrm{~kg}$ ) and height was measured using a fixed measuring tape with resolution $0.5 \mathrm{~cm}$. Volunteers were classified as overweight or obese based on BMI: $\mathrm{BMI} \geq 25 \cdot 0-29 \cdot 9 \mathrm{~kg} / \mathrm{m}^{2}$ as overweight and $\mathrm{BMI} \geq 30 \cdot 0 \mathrm{~kg} / \mathrm{m}^{2}$ as obese. Waist circumference was measured using a flexible measuring tape placed firmly and evenly around the abdomen directly above the hip bone. None of the volunteers had a chronic disease that would influence BMI, such as cancer or diabetes. A brief questionnaire on diet and income was provided to determine monthly income and monthly food expenditures. Income groups were created by dividing the sample into income quartiles and monthly incomes are presented in \$US using the mean exchange rate for the year in which the particular subject was interviewed.

\section{Statistical methods}

Differences between groups were analysed using Student's $t$ test and all data were found to be normally distributed. Differences between income groups were tested using one-way ANOVA. Statistical analyses were conducted using the SPSS for Windows statistical software package version $13 \cdot 0$ (SPSS, Inc., Chicago, IL, USA) and statistical significance was set at $P<0 \cdot 05$.

\section{Results}

Physical and income characteristics of the sample studied are presented in Table 1 . The prevalence of overweight and obesity in the total sample was $38.3 \%$ and $5.3 \%$, respectively, with a greater proportion of overweight and
Table 1 General characteristics of adults surveyed on diet and health in Sofia, Bulgaria, 2004-2006

\begin{tabular}{|c|c|c|}
\hline Variable & $n$ & $\%$ \\
\hline Total group & 1006 & \\
\hline Male & 453 & $45 \cdot 0$ \\
\hline Female & 553 & $55 \cdot 0$ \\
\hline \multicolumn{3}{|l|}{ Age group } \\
\hline $19-30$ years & 204 & $20 \cdot 3$ \\
\hline $30-60$ years & 470 & $46 \cdot 7$ \\
\hline $60-75$ years & 299 & $29 \cdot 7$ \\
\hline$>75$ years & 33 & $3 \cdot 3$ \\
\hline \multicolumn{3}{|c|}{ Income quartile (mean monthly income) } \\
\hline$<25$ th (\$US 179) & 209 & $24 \cdot 8$ \\
\hline 26th-50th (\$US 406) & 204 & $24 \cdot 2$ \\
\hline 51st-75th (\$US 655) & 239 & $28 \cdot 4$ \\
\hline 76th-100th (\$US 1210) & 191 & $22 \cdot 6$ \\
\hline \multicolumn{3}{|c|}{ Prevalence of overweight by age } \\
\hline Total & 385 & $38 \cdot 3$ \\
\hline $19-30$ years & 22 & $10 \cdot 8$ \\
\hline $30-60$ years & 165 & $35 \cdot 1$ \\
\hline $60-75$ years & 177 & $59 \cdot 2$ \\
\hline$>75$ years & 18 & $54 \cdot 5$ \\
\hline \multicolumn{3}{|l|}{ Prevalence of obesity by age } \\
\hline Total & 53 & $5 \cdot 3$ \\
\hline $19-30$ years & 1 & $0 \cdot 5$ \\
\hline $30-60$ years & 29 & $6 \cdot 2$ \\
\hline $60-75$ years & 20 & $6 \cdot 7$ \\
\hline$>75$ years & 3 & $9 \cdot 1$ \\
\hline \multicolumn{3}{|c|}{ Prevalence of overweight by sex } \\
\hline Male & 203 & $44 \cdot 8$ \\
\hline Female & 179 & $32 \cdot 4$ \\
\hline \multicolumn{3}{|l|}{ Prevalence of obesity by sex } \\
\hline Male & 27 & $6 \cdot 0$ \\
\hline Female & 26 & $4 \cdot 7$ \\
\hline
\end{tabular}

Overweight defined as $\mathrm{BMI}=25 \cdot 0-29 \cdot 9 \mathrm{~kg} / \mathrm{m}^{2}$; obesity defined as $\mathrm{BMI} \geq$ $30 \cdot 0 \mathrm{~kg} / \mathrm{m}^{2}$.

obesity among men than women $(44.8 \% \quad v .32 \cdot 4 \%$ and $6 \cdot 0 \% v \cdot 4 \cdot 7 \%$, respectively). The prevalence of both overweight and obesity increased with age. The reported mean monthly income (\$US 645) was slightly higher than the per capita income for Sofia (\$US 572) and nationally (\$US $288)^{(11)}$, but the fact that we were sampling adults who were frequenting food retail sites could explain this observation because we were not able to capture the lowerincome households that may rely on other sources for food.

Prevalence data on overweight and obesity by gender and income are presented in Table 2. In the total sample, the lowest income quartile had significantly higher BMI compared with the upper three quartiles, but BMI was not significantly different between the third and fourth quartiles. As gender is related to both income and BMI, we split the data by gender to see if the same patterns persisted. For men, there appeared to be a U-shaped relationship between income and BMI with the lower two and highest income groups having a higher BMI than the third quartile. A similar pattern was observed for waist circumference. For women, BMI decreased as income increased except for the highest two quartiles, which were not significantly different. The waist circumference of women was largest for the lowest income quartile, but was not different between the highest three quartiles. 
Table 2 Prevalence of overweight and obesity by income among adults in Sofia, Bulgaria, 2004-2006

\begin{tabular}{|c|c|c|c|c|c|}
\hline & \multirow[b]{2}{*}{ Income quartile } & \multicolumn{2}{|c|}{ BMI $\left(\mathrm{kg} / \mathrm{m}^{2}\right)$} & \multicolumn{2}{|c|}{ Waist circumference $(\mathrm{cm})$} \\
\hline & & Mean & $95 \% \mathrm{Cl}$ & Mean & $95 \% \mathrm{Cl}$ \\
\hline \multirow[t]{4}{*}{ Total } & $0-25$ th & $25 \cdot 7^{\mathrm{a}}$ & $25 \cdot 3,26 \cdot 2$ & $82 \cdot 3^{a}$ & $80 \cdot 8,83 \cdot 9$ \\
\hline & 26th-50th & $24 \cdot 7^{\mathrm{b}}$ & $24 \cdot 4,25 \cdot 1$ & $78 \cdot 6^{\mathrm{b}}$ & $77 \cdot 4,79 \cdot 9$ \\
\hline & 51st-75th & $23 \cdot 7^{c}$ & $23 \cdot 3,24 \cdot 1$ & $77 \cdot 6^{b}$ & $76 \cdot 1,79 \cdot 1$ \\
\hline & 76th-100th & $24 \cdot 2^{\mathrm{b}}$ & $23 \cdot 9,24 \cdot 1$ & $81 \cdot 3^{a}$ & $80 \cdot 0,82 \cdot 6$ \\
\hline \multirow[t]{4}{*}{ Men } & $0-25$ th & $26 \cdot 1^{a}$ & $25 \cdot 3,26 \cdot 9$ & $88 \cdot 0^{\mathrm{a}}$ & $85 \cdot 3,90 \cdot 7$ \\
\hline & 26th-50th & $25 \cdot 3^{\mathrm{a}}$ & $24 \cdot 9,25 \cdot 7$ & $83 \cdot 6^{\mathrm{b}, \mathrm{c}}$ & $82 \cdot 1,85 \cdot 1$ \\
\hline & $51 \mathrm{st}-75 \mathrm{th}$ & $24 \cdot 3^{b}$ & $23 \cdot 8,24 \cdot 8$ & $83 \cdot 5^{c}$ & $81 \cdot 6,85 \cdot 5$ \\
\hline & 76th-100th & $25 \cdot 5^{\mathrm{a}}$ & $25 \cdot 1,25 \cdot 9$ & $88 \cdot 2^{d}$ & $86 \cdot 6,89 \cdot 8$ \\
\hline \multirow[t]{4}{*}{ Women } & $0-25$ th & $25 \cdot 6^{\mathrm{a}}$ & $24 \cdot 9,26 \cdot 3$ & $79 \cdot 5^{\mathrm{a}}$ & $77 \cdot 6,81 \cdot 4$ \\
\hline & 26th-50th & $24 \cdot 3^{b}$ & $23 \cdot 7,24 \cdot 8$ & $74 \cdot 7^{b}$ & $73 \cdot 4,76 \cdot 1$ \\
\hline & 51 st-75th & $23 \cdot 3^{b, c}$ & $22 \cdot 7,23 \cdot 8$ & $72 \cdot 8^{b}$ & $71 \cdot 2,74 \cdot 5$ \\
\hline & 76th-100th & $22 \cdot 9^{c}$ & $22 \cdot 4,23 \cdot 4$ & $76 \cdot 8^{\mathrm{b}}$ & $72 \cdot 3,75 \cdot 3$ \\
\hline
\end{tabular}

$\overline{a, b, c, d}$ For each group, mean values within a column with unlike superscript letters were significantly different $(P<0 \cdot 05)$.

\section{Discussion}

As Bulgaria continues to develop, the need to monitor chronic metabolic conditions such as obesity is great given the costs of these diseases in both medical and economic terms and their potential to threaten continued development ${ }^{(12)}$. The present data, the first to report BMI and income for adults in Bulgaria, suggest that persons of lower income and older adults are more likely to have higher BMI compared with those with higher income and younger adults. Unfortunately, without comparable data from the 1980s, we are unable to describe any real trend in obesity following the economic transition of 1991. Still, we are able to discuss potential factors that may explain some of our observations, such as the role of food marketing or unemployment on diet and activity.

In terms of diet and food marketing following the transition of 1991, Bulgaria is undergoing rapid changes as the number of large supermarkets has increased over the past 10-15 years. Food availability at the neighbourhood level is one possible environmental determinant of diet as differences exist by retail site and location in the cost and availability of healthful foods ${ }^{(13,14)}$. There is also an association between the availability of retail sites with healthful foods and obesity ${ }^{(15)}$. Thus, for countries only now being exposed to such changes, it may be expected that obesity will increase as cheaper, energy-dense foods are introduced and marketed. However, a key challenge to deciphering this mechanism rests with the economic status of persons shopping at different retail sites.

Given that income and urbanization are two significant predictors of obesity for many countries, it is of particular importance to compare the present results with other national data. First, income appears to be a stronger predictor of both under- and overnutrition in middleincome countries ${ }^{(16-18)}$. In Bulgaria, where the average household spending for food is $41 \%$ of monthly income, the highest prevalence of inadequate nutritional status was estimated among the poorest study group ${ }^{(19)}$. Thus, the data on overweight/obesity from the present survey are similar to those reported from the national survey of 2004 , where the proportion adults aged 30-60 years who were overweight was $43 \%$ and $34 \%$ for men and women, respectively. However, income may simply act as a proxy for dietary intake and few studies in Bulgaria, including the national household survey, assessed both BMI and diet, a void filled with the present study on diet and economics in Bulgaria.

In terms of economics, the shift from centralized to market economies creates economic turmoil and subsequent changes in diet and health. In Poland, the BMI of young men did not change during the early period of the economic transition, but the BMI of all adults did increase between 1995 and $2001^{(20)}$. In Russia, the prevalence of obesity increased from $13 \%$ to $16 \%$ among adults during their period of transition ${ }^{(5)}$. For Bulgaria, only a few studies have reported BMI. The mean BMI of adults living in Sofia and Veliko Tournovo in the late 1990s was estimated at $26 \mathrm{~kg} / \mathrm{m}^{2}$ for men and $27 \mathrm{~kg} / \mathrm{m}^{2}$ for women ${ }^{(21,22)}$, but these values are based on a random sample of adults who participated in a clinical trial for which only $64 \%$ of all subjects invited actually participated. Unfortunately, we have not found data on BMI in the 1980s to which these values and the ones from the present study could be compared.

While the potential explanations for our observations may be valid and plausible, there are inherent challenges to the data we collected, challenges that could either mediate or attenuate these relationships. First, the data we collected could be biased as we relied on participant compliance to collect data and subject bias could result in an over- or underestimation of income. However, it is unlikely that subject bias would result in a systematic bias by both income and body weight. Second, our measurements were conducted in a field setting using available infrastructure and minimal clothing for weight measurements. Such factors would perhaps increase or decrease a subject's BMI to a small degree, but not produce a differential increase or decrease in the prevalence of overweight or obesity based on BMI. Finally, our data 
are based on a cross-sectional survey and do not permit us to delve into causal pathways or trends associated with economic and dietary changes. Nevertheless, these data are valuable given the general lack of data on obesity among adults in Bulgaria and provide a fairly clear 'snapshot' of the current status of adults living in this transitional country.

In conclusion, on the basis of the present data, obesity does not appear to be a serious public health problem among adults living in Sofia, Bulgaria. However, our data do suggest that persons of lower income may be more likely to be overweight and obese and contribute to the burden of chronic metabolic diseases in the EU. Therefore, it is of utmost priority for nutrition and development experts to better understand those forces acting on the citizens of Bulgaria at this economically and nutritionally vulnerable period of time and as a new member of the EU.

\section{Acknowledgements}

We would first like to thank the many persons who volunteered to participate in this study and also the numerous staff members without whom the data collection would not have been possible. This work was supported by a cooperative agreement with the US Department of Agriculture Foreign Agricultural Service, Washington, DC.

This study was funded by the US Department of Agriculture and there are no conflicts of interest for any of the authors listed on this manuscript. All authors contributed to the study design, data collection and manuscript preparation under the direction of the corresponding author.

\section{References}

1. de Onis M \& Blossner M (2000) Prevalence and trends of overweight among preschool children in developing countries. Am J Clin Nutr 72, 1032-1039.

2. Prentice AM (2006) The emerging epidemic of obesity in developing countries. Int J Epidemiol 35, 93-99.

3. Popkin BM (2004) The nutrition transition: an overview of world patterns of change. Nutr Rev 62, S140-S143.

4. Kim S, Popkin BM, Siega-Riz AM, Haines PS \& Arab L (2004) A cross-national comparison of lifestyle between China and the United States, using a comprehensive crossnational measurement tool of the healthfulness of lifestyles: the Lifestyle Index. Prev Med 38, 160-171.
5. Jahns L, Baturin A \& Popkin BM (2003) Obesity, diet, and poverty: trends in the Russian transition to market economy. Eur J Clin Nutr 57, 1295-1302.

6. Vatralova K, Petrova S, Angelova K, Ivanova L, Duleva V, Baikova D, Iordanov B, Ovcharova D, Vukov M \& Duneva Z (2000) National Dietary and Nutritional Status Survey of the Population in Bulgaria, 1998. Hyg Public Health 43, 51-54.

7. Rangelova R (2003) Bio-demographic change and socioeconomic trends in Bulgaria. Econ Hum Biol 1, 413-428.

8. Ivanova L, Dimitrov P, Ovcharova D, Dellava J \& Hoffman DJ (2006) Economic transition and household food consumption: a study of Bulgaria from 1985 to 2002. Econ Hum Biol 4, 383-397.

9. Parizkova J (2000) Dietary habits and nutritional status in adolescents in Central and Eastern Europe. Eur J Clin Nutr 54, Suppl. 1, S36-S40.

10. Koleva M, Nacheva A \& Boev M (2005) Somatotype, nutrition, and obesity. Rev Environ Health 15, 389-398.

11. World Bank Group (2007) Country Brief: Bulgaria. Washington, DC: WBG.

12. Wang G \& Dietz WH (2002) Economic burden of obesity in youths aged 6 to 17 years: 1979-1999. Pediatrics 109, E81.

13. Wechsler H, Basch CE, Zybert P, Lantigua R \& Shea S (1995) The availability of low-fat milk in an inner-city Latino community: implications for nutrition education. $\mathrm{Am} \mathrm{J}$ Public Health 85, 1690-1692.

14. Winkler E, Turrell G \& Patterson C (2006) Does living in a disadvantaged area entail limited opportunities to purchase fresh fruit and vegetables in terms of price, availability, and variety? Findings from the Brisbane Food Study. Health Place 12, 741-748.

15. Morland K, Wing S, Diez Roux A \& Poole C (2002) Neighborhood characteristics associated with the location of food stores and food service places. Am J Prev Med 22, 23-29.

16. Pomerleau J, McKee M, McKee M, Robertson A, Vaask S, Pudule I, Grinberga D, Abaravicius A \& Bartkeviciute R (2002) Food security in the Baltic Republics. Public Health Nutr 5, 397-404.

17. Filozof C, Gonzalez C, Sereday M, Mazza C \& Braguinsky J (2001) Obesity prevalence and trends in Latin-American countries. Obes Rev 2, 99-106.

18. Popkin BM \& Doak CM (1998) The obesity epidemic is a worldwide phenomenon. Nutr Rev 56, 106-114.

19. National Statistical Institute (2006) Annual Statistical Report for Bulgaria. Sofia: NSI.

20. Koziel S, Welon Z, Bielicki T, Szklarska A \& Ulijaszek S (2004) The effect of the economic transition on the body mass index of conscripts in Poland. Econ Hum Biol 2, 97-106.

21. Georgieva LM (2001) Risk Factor Surveillance for Coronary Heart Disease in Sofia, Bulgaria. Cambridge: Cambridge University Press.

22. Vasilevski N, Tulevski B, Vukov M, Ilieva P, Marinova P \& Iordaiov L (1998) Risk factors for health of the population aged 25-64 years in the demonstration area Veliko Tournovo of the CINDI-Bulgaria Program. Promotsia na Zdrave 3, 1-88. 